Volume 3

Number 3 Virtual Platforms: Spaces of Control

and Contestation

2018

\title{
The Unfree Space of Play: Emergence and Control in the Videogame and the Platform
}

Logan Brown

Indiana University, Bloomington

Follow this and additional works at: https://digitalcommons.uri.edu/mgdr

Part of the Anthropology Commons, Business Analytics Commons, Communication Technology and New Media Commons, Critical and Cultural Studies Commons, Economics Commons, Marketing Commons, Mass Communication Commons, Other Business Commons, Other Film and Media Studies Commons, Science and Technology Studies Commons, Social Media Commons, and the Sociology Commons

\section{Recommended Citation}

Brown, Logan (2018) "The Unfree Space of Play: Emergence and Control in the Videogame and the Platform," Markets, Globalization \& Development Review. Vol. 3: No. 3, Article 2.

DOI: 10.23860/MGDR-2018-03-03-02

Available at: https://digitalcommons.uri.edu/mgdr/vol3/iss3/2

This Article is brought to you for free and open access by DigitalCommons@URI. It has been accepted for inclusion in Markets, Globalization \& Development Review by an authorized editor of DigitalCommons@URI. For more information, please contact digitalcommons-group@uri.edu. 
The Unfree Space of Play: Emergence and Control in the Videogame and the Platform

\section{Markets, Globalization \& Development Review}
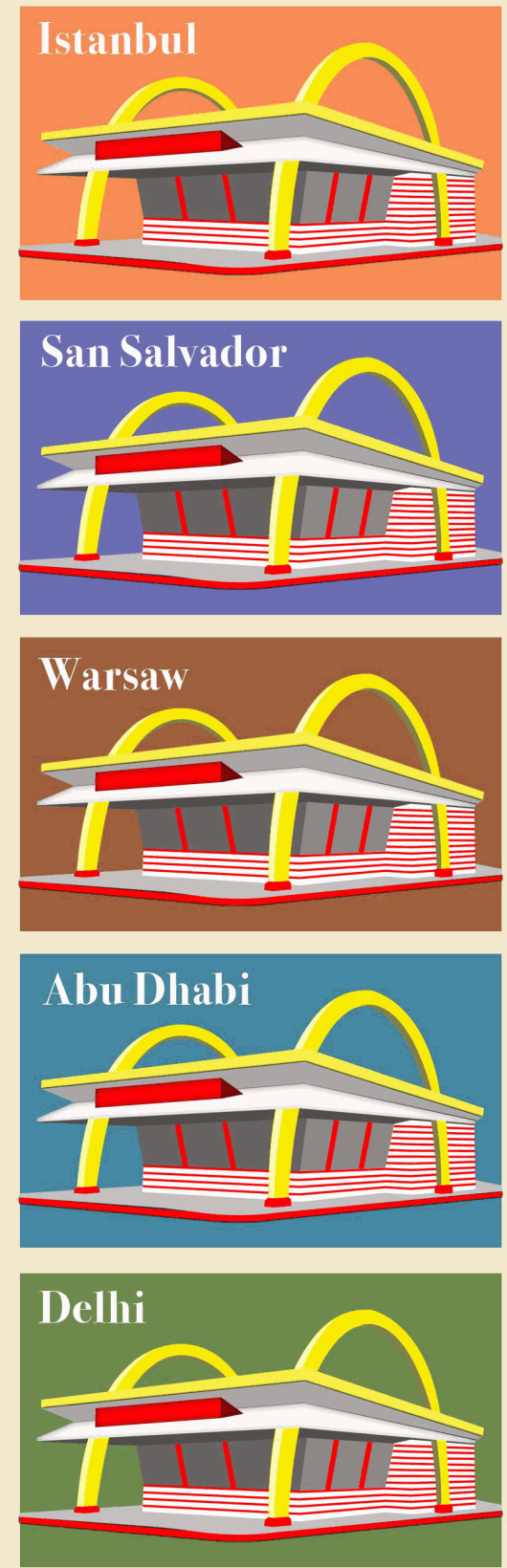
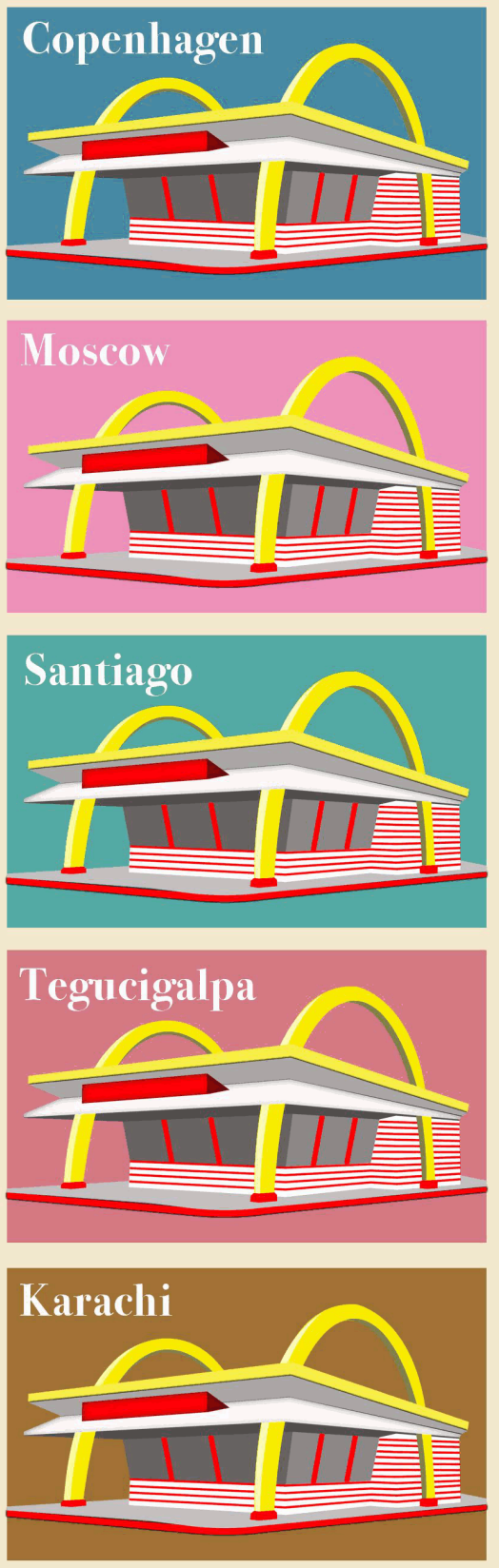
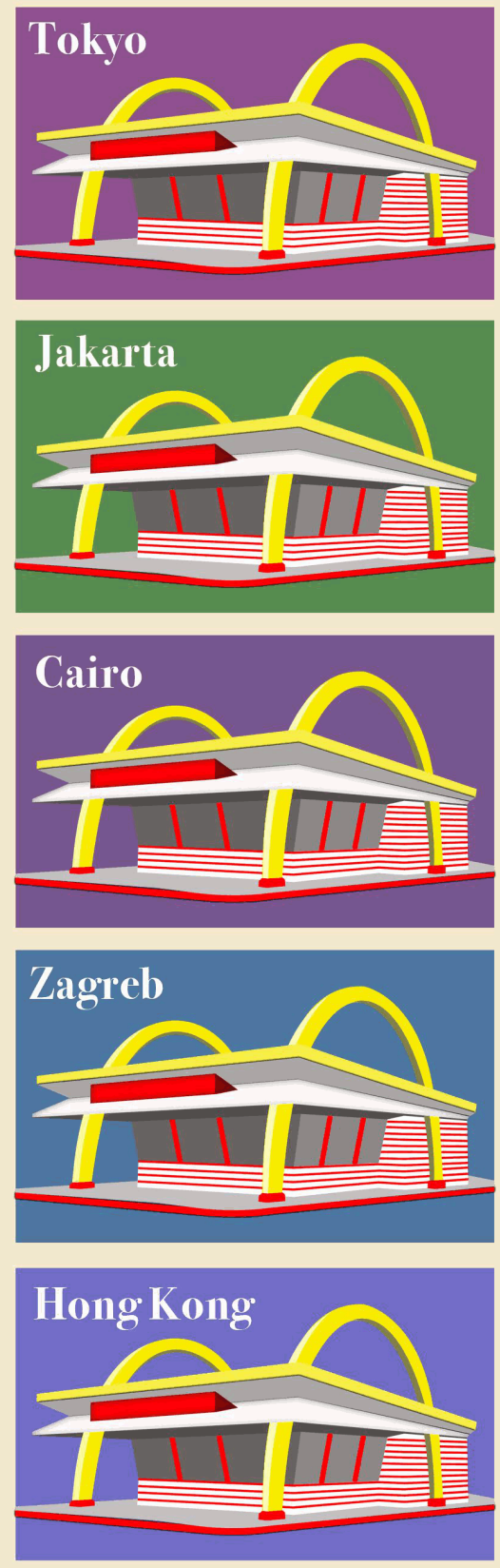

This article is available in Markets, Globalization \& Development Review: https://digitalcommons.uri.edu/mgdr/vol3/ 


\section{The Unfree Space of Play: Emergence and Control in the Video Game and the Platform}

Digital technologies have radically altered modes of cultural, economic, and social production while also blurring the lines between them. A deluge of terms has crashed over different discursive spheres in an attempt to pin down this historical moment: late capitalism, postmodernism, network society, the society of control, platform capitalism, ludocapitalism or, more succinctly, Empire as Michael Hardt and Antonio Negri (2000) use the term, a totalizing global order. The different valences and specificities undergirding these terms keep them somewhat separate - they are not perfect synonyms for one another-but they all share certain similarities. They all acknowledge the rise of a new form of capitalist production or reproduction-a sea-change in the technologies that allow people and groups to communicate, a tendency toward more decentralized, rhizomatic forms of control, a move away from monolithic hierarchical arrangements, so on and so on.

We have moved past the industrial era dominated by the Foucauldian mechanisms of discipline, of which the enclosed and separate spaces of the factory and the school are paradigmatic, into a strange new world characterized by "ultrarapid forms of free-floating control" (Deleuze 2009, p. 90). The enclosure has become a mold, a modulation. The rigid definition in time and space has been exploded leaving the inside/outside dichotomy, alongside the mass/individual and now/later pairs, deeply troubled. Now one never leaves the site of production as long as one has access to e-mail and teleconferencing, one never "finishes" school, one never exists in the here and now but rather "a sort of endless digital Now" (Gibson 2012, p. 44) always with one foot in the near future. The factory itself gives way to the corporate platform, "generative mechanisms, engines that set the terms of participation according to fixed protocols" (Bratton 2015, p. 374), platforms like Google, Facebook, Uber, YouTube, etc which connect us and define our actions. The breakdown of those dichotomies which felt so naturally suited to cause-and-effect, binary thought has led to an age governed by paradox, with perhaps one central one: in the society of control, in which those fortunate enough to have ready access to the internet can choose from all its treasures, an endless cornucopia of choice, how are we subject to more control than ever? We should look to videogames - the medium of this century - and the platform, this century's factory-and to the ways that they facilitate and restrict; in short how they modulate. It is one thing to 
recognize that "in societies of control there is both an increase in openness and an increase in control" (Galloway and Thacker 2007, p. 73). It is another to recognize that this paradox extends and broadens into a designing for, and embracing of, the unexpected, the contingent.

This essay aims to shed some light on the way that platforms and games have begun merging and how their dependence upon emergent behaviors situates them within the society of control. The videogame and the platform offer us the two halves of the logic of control. The videogame shows us how algorithmic affordances, which "fetishize control" (Galloway 2006, p. 93) generate an illusion of choice useful for governing biopower. The platform, the videogame's twin, reterritorializes rhizomatic space allowing for a new centralization in a rhizomatic world-terms and concepts which will be elucidated below. Their growing together is as inevitable as it is ominous.

Let us begin by looking at the current state of videogames, the valorization of emergence currently prevalent in the industry, and the ways in which the aesthetics of emergence overlap with the functioning of platforms.

\section{Games}

The great paradox of the game is that it is fundamentally defined by rules and limitations, yet is experienced as a release from the constraints of life and the world. Eric Zimmerman (2004): "play exists both because of and despite the more rigid structures of a system" (p. 159). The complex behaviors and peculiar individuality of each play session arise from this simple contradiction. A player's distinctive play style in a game like chess cannot transcend the rules of chess, but is an expression of his or her individual talents and understanding of the game within the game. Likewise, no two games of a sport like basketball are ever truly identical. The players cannot 'break' the rules, but within the heavily constrained time and space of a game of basketball there is a nearly infinite (sub)set of possible actions which ensures the uniqueness of character of a player and of any single game, all of which is only meaningful as a result of the game's rules. All of those unique characteristics that arise during play and which are the evidence of a well-crafted system-yet which are impossible for the game's designer to anticipate-are called emergent. Designers refer to unexpected actions that are technically allowable by the game's strictures emergent behaviors. The unscripted stories that people form in the field of play, the close scrapes, near misses, and last-minute underdog victories, are called emergent narratives. Games - most analogue games and more and more videogames - which privilege a degree of behavioral 
openness over tightly delimited, largely linear progress (Juul 2005, p. 76) are, then, called emergent games.

Preoccupation with emergence in games represents a particular design philosophy which privileges mechanical complexity over some of the more conventional selling points of games - graphical fidelity, narrative immersion, character design - in order to maximize the quality which is exclusive to the medium. It is a thoroughly algorithmic approach to design deeply rooted in the medium essentialism of the early ludologists, scholars of the early-to-mid 2000's like Jesper Juul and Espen Aarseth who understood games as sets of rules and algorithms first and foremost. The purpose of the game viewed from the perspective of rules and algorithms rather than narrative necessitates a change in thought. Viewed from a cinematic perspective-one of the ludologists' most hated sins-games which are narratively and visually rich supported by limited interactivity in the vein of Don Bluth's Dragon's Lair, are successful. But from the algorithmic, ludological perspective these games represent spectacular failures. Rather, the narrative complexity should emerge from the rules themselves. Zimmerman's perfect example is Ms. Pac-Man, "a narrative in which procedures, relationships, and complex systems dynamically signify. It is the kind of narrative that only a game could tell" (p. 162). The story is a story of the player and the player's experience, which must differ from the experiences of others in a meaningful way.

While a full history of emergence in games is well outside the bounds of this essay, suffice it to say that the design strategies aimed at maximizing emergent experiences and their associated genres change with consumer taste, fads, and simple, raw processing power. In the 1990 's the ascendant mechanics-heavy genres were fighting games and complex immersive sims-i.e. systems-heavy simulations of fantastic environments). In the 2000s, the popularity of games like Everquest and Runescape paved the way for the explosive popularity of Blizzard's World of Warcraft as the endless novelty of the MMORPG captured people's social imagination. But the highest profile and most enduring games in the last several years have been highly competitive, frequently updated multiplayer games like League of Legends, Dota 2, and Overwatch. The finer points of their play vary wildly: League and Dota 2 throw players into a top-down, real-time-strategy style map while Overwatch is what is typically called a "hero shooter," a game in which players run and gun through the enemy team in first-person to try and fulfill different game modes' objectives. Despite their ludological differences, all three fit nicely into the gaming industry's current craze: games as a service (Schreier 2017), an economic model that aims to prolong the life-and profitability- 
of a game indefinitely. Games as a service is the attempt by developers and producers to recast individual games as platforms of networked activities and communications that do not end. These games thrive on emergence. Their designers work to maintain a constant flux in character strength and the viability of particular play styles in order to keep players away from dominant strategies. To excel, players must not only play constantly to remain familiar with the nuance of the game throughout these changes but must also work on the game outside of its bounds, through sites like mobafire.com and leaguecraft.com, to study up on character strengths, item optimization, team synergies, tactics, and so forth.

Minecraft is the second-best selling game of all time-after the venerable Tetris-and it could not be more different from e-sports darlings like Overwatch and League of Legends. The premise is simple: the game offers a nigh-endless expanse of terrain of various types that the player can mine for materials in order to then build whatever his or her heart desires out of blocks. Players build massive structures in this game with no extrinsic motivation; they build full scale replicas of Game of Thrones' Westeros simply to have done so (Domanico 2015). There is very little hard-coded competition in Minecraft. The game sports survival and story modes, but the game's true selling-point is its free-play mode, in which players roam a voxelated, nigh-infinite realm with the aim to build things. Minecraft is the emergent game par excellence; developer Mojang has created a game world that allows players free reign to express themselves, while the networked connectivity of the game - the key to its success (Isbister 2016, p. 43) - ensures that the prospect of displaying one's creation to other players offers a soft, social goal that structures player behavior. Minecraft is only emergence. The endlessly reconfigurable sandbox it provides to players only has as much meaning as players express through it. It cannot be beaten or finished-one player spent years documenting his attempt to simply reach the edge of the game's map in a series of over 600 videos; as of 2018 he has not even come close (Kurtjmac 2018).

Jean Baudrillard (2003) has written that "the end is also the finality or purpose of something, that which gives it meaning. And when you are in processes developing in a chain reaction, which, beyond a certain critical mass, become exponential, they no longer have any finality or meaning ... we are already in an exponential, unlimited form in which everything develops in the void, to infinity, without any possibility of reapprehending it" (pp. 59-61). The endlessness of emergent games satisfies the platform's need for insatiable growth as well as becoming an expression of it, always 
reconfiguring and re-actualizing without collapsing into finality. There is no end, no inside and outside to the modern videogame. They are not the virtual worlds that critics, scholars, and futurists envisioned in the aughtsthough they took notes from earlier MMO's-but rather full-blown APIenabled platforms through which people can play the games, purchase virtual commodities, chat, and strategize unconstrained by the bounds of the magic circle. Games join all the other aspects of postmodern society that proliferate endlessly into the void. Like the modern state of crisis (Hardt and Negri 2000) in which states rule through perpetual exception to the norm via ostensibly temporary measures epitomized by the PATRIOT Act; like warfare, which becomes "banal" (Dyer-Witheford and De Peuter 2009) and devolves into continuous police action without specific goals; like narratives and franchises (Ndalianis 2004) which endure in theaters and on screens indefinitely, videogames have no ending, placing them formally and firmly in line with these other phenomena.

Yet games have always been without end. One cannot complete football nor finish cricket. Even Ms. Pac-Man, Zimmerman's alreadyancient example, was conceived of by a small company called General Computer as an update board referred to as an "enhancement kit" to make Pac-Man less soluble after fans found dominant strategies-i.e. universally ideal strategies - to maximize scores in the original game (Kent 2001, pp. 167-173). Games and their dynamic narratives have always derived their lasting strength from their emergent properties. Whence the difference, whence the platforming of games? The difference now is that games are interconnected with vast extractive apparatuses which analyze the emergent gap between rules and freedom, record the myriad executions of player actions, and then double as pipelines for modification by pushing through updates in real-time. Games' emergent properties reflect back on the rules and algorithms themselves. The ontology of the game is in perpetual flux, shaped by the fluid and myriad actualizations of their complex rules, wearing away any imperfect edges in the system.

The videogame should be understood as very much like and yet very much unlike other franchise entertainment, which depends upon rampant serialization-think Marvel or Star Wars - really any Disney property - to ensure a steady stream of profits to the studio. On the one hand, videogames also exist primarily as commodities, objects to be bought and sold in order to generate revenue, no different from any other commodity to be melted down into the universal medium of capital. All the tactics implemented by manipulative triple-A studios ultimately feed back into the one central pursuit of profit. But on the other, videogames also break past even the reproductive logic of film and television. New 
installments of a successful Marvel franchise may come out regularly as creatives generate ever-more-sprawling hyperdiegetic worlds that can conceivably house an infinite number of distinct stories, but only videogames can truly be said to impel user-players to occupy the spaceexcept perhaps platforms, which I will address shortly-and pursue goals dictated therein. The control of the videogame should also be understood as radically different from the analog game. What separates the videogame from the game, and the society of control from the disciplinary society, is the radical difference between algorithmic affordance and rule. The affordance offers a brand new way to interact with a virtual world, a game, other people, etc. The rule, meanwhile, is a sociolinguistically-fixed limitation that is only ever a pact between players. There is nothing physically stopping a bored child playing Monopoly from moving his or her piece wherever they want; only other players can do that, typically to the displeasure of the offending child. In the digital game, affordances are usually hard-coded into the system itself. They are perceived as liberating rather than restricting, even if they amount to the same restraint as traditional rulesets.

Platforms, as we shall see below, are fundamentally devices which feed off of the behaviors which emerge from their affordances by quantifying and storing vast amounts of behavioral data. They facilitate behaviors to their own gain. The game as a medium has typically only been interested in how it is played in order to further improve the gameplay experience. It directs much more explicitly by allocating intention through the "valorization of outcome" (Juul 2005, p. 36), but nobody much minded as long as games remained in their own magic circle of triviality. A major component of the platforming of the videogame comes with the adoption of data-focused techniques most often associated with platforms. Game designers have always looked to professional testers and focus groups to analyze the efficacy of play in a game, but the analytical capabilities of modern game platforms allow for a qualitatively new level of control.

Not only do individual games increasingly resemble platforms in their breadth and indeterminability, but gaming itself is increasingly invested in individual platforms which read and type player 'dividuals.' Stuart Brown (2010), for instance, has offered up eight player types: artist/creator, collector, competitor, director, explorer, kinesthete, storyteller, and joker (p. 65). Steam, a game distribution and play platform which commands somewhere between $50 \%$ to $70 \%$ of all PC game downloads (Grubb 2017), is the prime example. Steam's analytics can measure a player's libraries, play history, interpersonal chat interaction, 
etc while the client also links to Google Analytics to track pages visited inclient. Game consoles, long considered platforms, have also been mutating into connected platforms. The Playstation 4 has a 'share button' which allows players to blend their gameplay with Facebook, Twitch, and others with a single press. And of course players are most likely to share unexpected moments that others will not necessarily see in their own games. Emergence strikes again.

These games and their systems are always, finally, a means to profit. They encourage emergent behavior in order to remain relevant. This works both ways. Through distribution platforms like Steam or proprietary systems companies make for their own games-the League of Legends client, Ubisoft's Uplay-they become platforms that can and do measure and store all manner of player behaviors. This helps the endless cycle of patching keep games from being solvable-which is both an aesthetic virtue for the game and an economic virtue for the owner-rentier-while analytics provide not only behavioral but economic control by "[opening] the gates to new monetization opportunities, either through targeted advertising or, more frequently in the past few years, by allowing game developers to deduce when the most appropriate moment to suggest a micro-transaction within the game" (Freire et. al. 2016, p. 11). More aleatory practices on the part of developers through "random drops" and "loot boxes"-reward systems which grant players random in-game items based on the quantity and quality of their play-can be so effectively crafted to manipulate players that some regions are working to ban the practice (Shah 2017). The platforming of games is the converting of play into Hardt and Negri's biopower (2000), "in which the economic, the political, and the cultural increasingly overlap and invest one another" ( $p$. xiii) and establish a much tighter regime of social control, or what DyerWitheford and De Peuter (2009) have termed biopower play which, like actual biopower, is still governed to the same end: perpetual accumulation of capital, of data, and of attention which are themselves increasingly indistinguishable from one another.

\section{Platforms}

Not too long ago critics and designers used the term platform in order to describe largely physical devices: "specific hardware and software combinations, like a particular game console or mobile device with its own operating system, hardwired (inscribed and coded) chips, and input technologies (keypad, game controller, accelerometer) system, a number of formats, each with their own affordances and constraints" (Murray 2012, p. 34). The old notion of a platform has not left us yet - MIT Press's 
Platform Studies series still addresses the intersection of hardware with software design, and it serves us well to remember that no digital object exists outside a material base. But the conventional definition has been slowly supplanted in the past decade or so with the intensification of networking. The platform we know now is an altogether more abstract structure. Platforms today ultimately mediate everything - the social (Twitter, Facebook), the commercial (Amazon), the logistical (Google), the cultural (all of the above) - without the tangible constraints of apparent hardware specificity, with one of their few shared qualities being abstraction itself. The old hardware/software paradigm of platform definition conceived of the platform as an engine for virtualization, a machine which sustains, presents, and represents the virtual. The modern platform is, instead, itself virtual and only dubiously locatable. Benjamin Bratton's (2015) slightly more contemporary definition is appropriately involved: "a standards-based technical-economic system that simultaneously distributes interfaces through their remote coordination and centralizes their integrated control through that same coordination" ( $p$. 42). Nick Srnicek's (2017) definition, though simpler, is no less abstract: "At the most general level platforms are digital infrastructures that enable two or more groups to interact" (p. 43). He acknowledges non-digital platforms while arguing that their inefficiency renders them less than ideal in the current economic landscape (p. 134).

This definitional change speaks to a rampant virtualization, a deactualizing of economic and social centers into Deleuze's "ultra-rapid forms of free-floating control" (p. 90). The rigid material structures and institutions of the disciplinary society which govern by impressing ideological discipline onto political subjects through the strength of the system's walls and its subsequent contextualization evaporate into the networks. The physical bounds of the school, the barracks, the prison, the company disappear into algorithmic codes, and each become a "freefloating" context capable of being realized anywhere. The school extends indefinitely throughout one's life, beginning with the social obligation toward higher education and continuing with endless seminars, retreats, and re-training events even as e-mail and online classes transport the walls of the school to one's living room or a nearby coffee shop. The corporation exists not as a single building, but as a constantly renewed coalition of semi-autonomous agents, some housed inside company buildings tethered to one another only by fiber-optic cable while others exist in a limbo of precarity as contractors telecommuting from home and accessing the data necessary to perform their functions remotely. This hypothetical company is in perpetual need of actualization and re- 
actualization. Pierre Levy (1998) provides a lucid explanation: "the virtualization of the corporation consists primarily of transforming the spatiotemporal coordinates of work into a continuously renewed problem rather than a stable solution. The organizations center of gravity is no longer a group of buildings, workstations, and schedules, but a process of coordination" (p. 26-27). Look to the great titans of postmodern American industry: Google, Apple, Microsoft, YouTube, all companies whose products are platforms and which are themselves dependent upon platformed communication to sustain their trans-national bulk. In other words, all perfectly indicative of the global capitalist enterprise. Even the conventional industrial powers depend heavily on either subscriptions to industrial platforms or on proprietary platforms of their own in order to best coordinate and streamline the production process to shave the least fraction of a cent off each unit's cost (Srnicek 2017) via a kind of virtual Toyotism. The platform has supplanted the factory, if obliquely, as the essential form and symbol of economic power. It is the engine which virtualizes the walls of the factory so that they might be re-laid elsewhere at any time.

This is where the concept of the rhizome and the process of deterritorialization and reterritorialization become key to explaining and understanding this centralization. The rhizome is a radically flattened, nonhierarchical structure wherein each point is capable of connecting to any other without resorting to mediation or a central power. As such, it represents what the early techno-utopian internet would and could be, a topic discussed ad nauseam elsewhere. Yet the rhizome, in Deleuze and Guattari's (1987) usage, also forms the map of the interrelationships that occur within the individual, between individuals, between groups, between concepts, individuals, assemblages, and so on. "The rhizome pertains to a map that must be produced, constructed, a map that is always detachable, connectable, reversible, modifiable" (p. 21), neither one nor many yet both. And that map is "produced," modified by the process of deterritorialization, the escape of an individual, group, object, quality, concept, etc. from its milieu into a new one-reterritorialization-or off into its own plane-absolute deterritorialization.

Individual people, objects, even ideas and qualities deterritorialize along what Deleuze and Guattari call "lines of flight," the vectors along which they leave their old contexts and functions to enter new ones. They write that "a group or individual creates the line rather than following it" ( $p$. 204), and in so doing form a new path in the rhizome rather than necessarily retracing lines already pathed. In this context, we might consider these paths to be reposting, hyperlinking, moving from one digital 
community to the next, spreading viral content, mutating memes, etc, all the behaviors which define networked communication and activity. The platform, then, serves as a central node in the rhizome according to its connective capacities, encouraging deterritorialization along lines of flight so that the platform can then absorb those lines into its own map, its own diagram. This is what emergence means to the platform: allowing and even designing for lines of flight that the extractive algorithms of the platform can then reify as its own territory. The greater the platform's capacity for reification, the greater its ability to provide individuals with a pool of raw, virtual abstraction they might actualize. The more those individuals actualize, the deeper the platform's pool, effecting a growing centralization by what McKenzie Wark (2004) calls the vectoralist class which "owns the means of realizing the value of these abstractions" ( $p$. 21).

The platform thrives off of - indeed depends upon - the networking of people. The vast apparatuses of interconnectivity that were envisioned as liberating powers for the masses proved to merely require different methods of monetization. The platform is precisely that which re-organizes that control: "The undifferentiated mass that by its simple presence was able to destroy the modern tradition ... appears now as a powerful productive force and an uncontrollable source of valorization" (Hardt and Negri 2000, p. 376). All that was needed was a way to better insinuate loci of power into the overly rhizomatic-from the perspective of capital and power-early net. In the most direct sense it is a business/technical model that requires that people participate in order to actualize the platform's naturally inert potential; there can be no Uber without users participating in the virtual system. This is the crude, forward facing half of the economic model by which Facebook makes its money and satisfies its raison d'être by generating ad revenue, Uber and Lyft provide a framework for ridesharing for which they pocket a percentage, while Amazon and Alibaba offer networked storefronts for digital retail. None of these can operate without the willing participation of an active user base. One could argue that since every platform is an abstract formal model designed for occupation by any and all that its most basic functions require an emergent constituency, that the exact configuration of actualization is understood from the start to be unknown. There is some truth to this, but one might make the same argument of the factory.

The real dependence on emergence comes from the back-end structure of the platform. Behind the scenes, every platform scrapes user interactions for data in order to better suit the desires of users-often unknown to the users themselves-to target advertising, to sell as 
resource to other firms, and to maintain control. Much like the game, the platform must make sure to maintain a sense of fairness among users by archiving every interaction to scour for abuses-one of the more admirable uses of unprecedented surveillance, one suspects-and for bugs or glitches to keep users siphoning through their digital choke points. An aura of fairness and of the sense of algorithmic affordance mentioned above insures that use will continue and that the major platforms become thicker and thicker nodes in the rhizome, which leads to better and greater quantities of data, thus improving services, and so on ad infinitum. Thus the platform depends upon emergence in order to find new types of data to extract and new changes to make in its perpetual slouching towards monopolization (Srnicek 2017). Basically, platforms thrive off the play that emerges from their formal structures, their affordances, and limits in much the same way as the videogame. Zimmerman's (2004) definition of play as "the free space of movement within a more rigid structure" which "exists both because of and also despite the more rigid structures of a system" ( $p$. 159) holds just as true of the platform as of the game. This can be fruitfully conceived of in terms of intellectual profit: the platform must generate more knowledge than was coded into it in order to monetize the free labor of the general intellect.

Tizianna Terranova points out that the reality of the extractive process of free labor is not so simple-one cannot measure intellectual, creative, or affective contribution by the same simple, quantitative metrics that managers bring to bear on labor-time-and that there remains a kind of cultural accursed share to the gift economy of digital community that resists co-option by capital. She points out that "Knowledge workers need open organizational structures to produce, because the production of knowledge is rooted in collaboration" (Terranova 2003) in a space unimpeded by total extraction. Not every idea can or should be commodified into a paid blog, or a web-series, etc. The genius of the platform, like the game, then, is that it foregoes the traditional valorization model in which the stories of the masses are shaped into saleable products in the form of reality television and instead exploits the centralizing tendencies of network effects to chart off the most valuable social real estate and extracts value from simple presence there. In the same way that Blizzard did not care if you used the virtual space of World of Warcraft as a complicated chatroom rather than a game so long as you paid your monthly fee, the platform creates the open spaces necessary for communal labor and cleverly arrays it with algorithmic tools that simultaneously facilitate those processes and measures their success. 
The four companies mentioned earlier, Google, Apple, Microsoft, and YouTube, were all also participants in the National Security Agency's domestic spying program PRISM thanks to the centralization they bring to the web (Kaplan 2016). Control may increasingly depend upon economic forces to manipulate, but traditional sovereign powers can also leverage the re-centralizing effects of platforms toward their own ends. Yet it should be alarming to note that governments - the US government in this example, though any nation of the 5 Eyes and increasingly any nation at all - appeal to the platforms rather than the other way around. The platform's ability to encourage behaviors in order to capture them outstrips the capabilities of traditional government apparatuses. As Bratton (2015) points out, "platforms not only have geopolitical ramifications and implications; they are a geopolitical condition and constitution in their own right" (p. 122). So let it be known that while platforms can and do act as sovereign surveillance prostheses, their role in the society of control runs so much deeper than that. We see biopower at play once again: in the platform one cannot readily distinguish between the social, the economic, and the political.

But the platform needs to encourage use, to create vagaries in order to foster emergent behaviors before it can harvest that data. Compelling is generally out of the question. Thus platforms must, like most power-centers in the society of control, impel users, and no form is better suited to impelling, to channeling the desiring-machine, than the game. Gamification, after all, is just valorization rebranded. Many have argued that in the first years of the $21^{\text {st }}$ century, this realization has fostered a kind of world-wide gamification. Julian Dibbell (2006) called it ludocapitalism. McKenzie Wark (2007) calls it gamespace: "Play is no longer counter to work. Play becomes work; work becomes play. Play outside of work found itself captured by the rise of the digital game ... The utopian dream of liberating play from the game, of a pure play beyond the game, merely opened the way for the extension of gamespace into every aspect of everyday life" (p. 16) Under ludocapitalism, everything is recast as a kind of agonistic striving for victory, an unending cycle of self-betterment in the interest of besting others. Perpetual training, perpetual connection with the work environment (Lazzarato 1996), and perpetual quota-meeting have become the norm in order to achieve victory in an exaggerated form of capitalistic competition. With the ludic platform, we can add perpetual social engagement to that list.

Many platforms leave this vague. Platform gamification must remain relatively loose in setting objectives or they risk limiting the data by limiting emergence. YouTube encourages and rewards the breaking of viewer and 
subscriber records, both through higher monetization deals and oddly antiquated plaques to channels who manage to surpass certain arbitrary viewer thresholds. Snapchat and Timehop maintain a crude kind of scoring system that alerts users to their "streaks," or how many days in a row they have engaged with the platform, engaged with specific other "friends," etc. Grubhub, a food ordering platform, has distributed the usual "customer reward" discounts in the form of spinners and minigames to add a "lootbox" dimension to an otherwise mundane activity. Grubhub's (2015) website exhorts others to do the same: "Everyone loves a good game. Turn your loyalty program into a game and add an extra level of entertainment to the customer experience. Consider using a badging or ranking system. As customers rack up visits to your restaurant, they rise in rank, and the higher they go, the better the rewards they receive."

Gamification extends to less obvious platforms as well. Even the more staid, less public facing industrial platform faces gamification in the near future, as factory owners look for ways to wring out self-motivation from employees. Simple industrial tasks like the repetitive tightening of bolts can be gamified via a platform interface to encourage an unconscious flow-state in the worker, leading to more orderly and regular labor (Roh et. al 2016). This is not a particularly emergent practice, but one we can expect to see more of in the near future.

With the success of Pokemon Go breaking functional AR into the mainstream, we can also expect further use of platform enabled-as well as bankrolled and designed-AR technology to cast the impelling logic of the game-platform into real space. If one of gamification's great uses is educational (Bogost 2010, p. 245) then the society of control can easily use games to "educate" to its own ends-through a lucrative deal with one of the tech giants, no doubt. One of the games first developed by Pokemon Go developer Niantic while it was still attached to Google was an AR game called Ingress, in which players on two opposing teams compete with one another to tag landmarks and form "control fields." Bratton has pointed out that the "ludic demands of Ingress are to send people out into their cities training them to see, attack, and defend against the territorial incursions of enemies perceivable only through special software-enabled perspectives" (p. 242). This is effectively a recasting of earlier discourses surrounding joystick warfare (Penny 2004) and the military-entertainment complex, but one whose persistence helps to illuminate the lines running from platform-corporation to game to sovereign body. 


\section{Lessons}

So then the governing logic of our time is the property of emergence. If this is broadly true of network actions and especially true of platforms, what can the study of games tell us about the functioning of platforms? Firstly that we can reverse-engineer the design precepts governing platforms through the lens of game design. The purpose of the platform can be meaningfully concentrated to "continued use," and the engaging game is the one that players will play "again and again if something about the experience continues to engage them with 'variety, novelty, and surprise"' (Salen and Zimmerman 2004, p. 165). Veteran games journalist Leigh Alexander (2013), discussing the legendary Warren Spector's ideas on emergence, offered that designers aim to "create global rules versus specific, instanced behavior of objects and characters; build interlocking systems that are predictable and consistent but not pre-determined."

Game-platform convergence can expose the still-prevalent myth that expression through platforms is largely free. Games' status as fictions invites a cultural critique, and nobody would assert that what one does in the broadest sandbox game like Skyrim is constrained only by the limits of one's own imagination. Emergence is still a product of restraints, and breaking Skyrim or Deus Ex is still an expression not of the player, really, but of the system and its algorithms. What one does on Facebook, what one says on Twitter, or what one uploads to YouTube my seem free-"I can say whatever I want on here!"-but is still shaped by the affordances coded into each platform, though recent debates over the limits of freedom of speech have thrown this discrepancy into sharper relief. Game designer Harvey Smith has argued for "systemic level design" which privileges emergence because "it allows for more self-expression on the players' part; the players can solve problems the way they want to solve them rather than the way the game designers planned" (qtd. in Juul 2005, p. 77). But players are always still solving the same problem.

Emergence, the unplanned rising out of a deeply abstract system, is always finally an expression of the platform from which it is birthed and it returns to the platform as data. Whereas constant updates and patches keep the modern game of emergence from ever being solvable, the data tracking and accumulation technologies employed by platforms thrive off of new and unexpected data streams. Bogost (2008) has argued that emergent videogames "mark an important break in their rejections of 'natural' order, like the rejections [put forth by] Deleuze and Guattari" ( $p$. 151). The emergent game allows for the radical reappraisal and reconfiguration of the self through the degree and "type" of emergence allowable by the system. For Bogost, the game of emergence allows for 
an applied schizoanalysis—as Deleuze and Guattari call their practice-in that its low-level simplicity restores meaning to "free-form, localized maneuvers" which rely "on individual gestures, not on coordinating system operations" (p. 149). The central concern here is the perpetuation of openness rather than the rigidity of closed systems of self-hood, identity, etc. that potential latent in a network offers. Baldwin (2018) points out that this is perhaps most salient in the liberatory potential that avatar-crafting can offer trans players, both as a means for creating a space of selfhood foreclosed by actual space and as a "free-form, localized maneuver" of subversion against established gender constructs. But Bogost also warns us of the potential pitfall, that the rhizome always threatens to become a rigid structure itself, which dwarfs the individual connections and contributions it contains. The map overwhelms the territory, so to speak. The postmodern 'dividual,' in the game and on the platform is pre-defined contingently and rapidly by the system, with the system the only true message. The platform-game and the game-platform do dispense with the naturalistic fallacy, but only to reimpose a new nature. A la Baudrillard (2010), the emergent interaction of user and platform/game is "neither information nor communication, but referendum, perpetual test, circular response, verification of the code" (p. 75).

While the game helps us understand the way that platforms manage biopower by manipulating behavior, the platform can help us understand the consolidation of real power in the videogame.

\section{Conclusion}

The shift to designing for emergent behaviors in the game and the platform is fundamentally the tacit recognition of a broader conceptual shift in power relations under a capitalistic biopolitical regime. Biopolitical organization radically redefines the relations between the state, other loci of control, and the individual i.e. through the massification of the individual. Where the disciplining of the individual was once sufficient to ensure, in the perfect case, a compliant subject epitomized by the factory worker who recognized and obeyed the edicts of power, the modern user-subject unintentionally shapes power itself through his or her behavior. As Alexander Galloway (2006) has noted, "[if] diverse technical systems are flexible enough to accommodate massive contingency, then the result is a more robust system that can subsume all comers under the larger mantle of continuity and universalism" (p. 101). The key change that takes place with networked power becomes the recognition of informatic control as a far more potent tool. Foucault pointed out that the actions of individual subjects "are phenomena that are aleatory and unpredictable when taken 
in themselves or individually, but which, at the collective level, display constants that are easy, or at least possible, to establish" (Foucault qtd. in Galloway and Thacker 2007. p. 73). I argue that the next step past macroscale engagement with populations is the accounting for and successful management of the unpredictable itself through the expectation for and automatic capture of emergent behaviors.

All signs point toward a rapid intensification of this merging between the logic of games with the maps of platforms. In February 2018, Brice Morrison (2018), former lead designer of Zynga, a company known for its mobile and Facebook games, penned a piece entitled "The Next Surprise Billion Dollar Game Will Be On Alexa" in which he boldly proclaims -in the first line no less - that "I'm predicting by 2020 there will be a billion dollar game where the primary way to play is with your voice." Natural language play, the powerful Al necessary to make it work, and the intense complexity of the saleable data that Amazon would inevitably siphon off should give us pause. Since then, games have slowly and surely made their way onto that platform: a Pac-Man game, game tie-ins for Jurassic World as well as Westworld. While still a far cry from Morrison's billion dollar hit or even from really functional games, they are harbingers of things to come.

A little over a month after Morrison published his piece to Gamasutra, the Cambridge Analytica scandal broke, and millions of Americans were informed that their most trivial actions on Facebook had yielded data that had played at least some part in the outcome of the 2016 election. A profile by Carole Cadwalladr (2018) for The Guardian of Chris Wylie, the whistleblower who brought the scandal to light, offered more immediately distressing information. Midway through the piece, Cadwalladr relates a strange, almost humorous anecdote from an unnamed member of Cambridge University's Psychometrics Center (which produced papers of great influence on Wylie):

There was one [program] called You Are What You Like and it was demonstrated to the intelligence services. And it showed these odd patterns; that, for example, people who liked 'I hate Israel' on Facebook also tended to like Nike shoes and KitKats. There are agencies that fund research on behalf of the intelligence services. And they were all over this research. That one was nicknamed Operation KitKat.

This is the product of Facebook quizzes rather than games, but it is only a matter of time until categories like Stuart Brown's are turned to the same unpredictable ends. 
lan Bogost (2018), in his response to the revelations, published a piece in The Atlantic admitting to the world that a satirical game he had made in 2010 had captured the Facebook data of anybody who played it, simply because it was easier to accept the data than not. One month later, Newzoo reported that mobile gaming had surpassed $50 \%$ of all game sales across the globe (Wijman 2018) followed quickly by Bloomberg's reporting on a new Google startup to focus on the development of mobile games (Frier and Bergen 2018) which would require players to sign up with their phone numbers. "Users create accounts with their phone numbers, one of the people said. Google is considering it a social-media investment because once a game gets to a certain size, it's something of a social network by itself."

What most of this has led to is a renewed vigor among various public and private spheres to campaign for privacy rights on the internet. Privacy concerns in the vein of Cambridge Analytica and Bogost's Cow Clicker are important, but what must be kept in mind at all times is that this is only one small part, a symptom, of this formal consonance. In a sense, even the economic abuses which cloud this new system are symptomatic rather than essential. Rather, the overlapping of platforms and games into a vast abstract, formal apparatus should be first and foremost considered in its totality, as a totalizing force which, by its very virtuality, must be thought in its abstraction first, and then on through its particular dangers. In the execution of this essay, I have switched between these registers, the general/formal and the particular, the molar and the molecular, in order to offer an entrée into both aspects of what is doubtless a massively complex virtual territory.

What can we do, then, to stem the tide? Deleuze (2009) counseled that "there is no need to fear or hope, but only to look for new weapons" (p. 90), but our arms are slow in coming. A return to self-contained forms of expression and action would be regressive, merely an exchange of today's problems for yesterday's. The problems of rigid structures and arboreal models gave us the 'solutions' that now plague the society of control. Current trends towards the reification of platforms through the internet of things will continue to erode the division between the object and the platform. Likewise, continuous pushes toward AR technology will eventually yield fruit, and the thin membrane separating the game from life will disintegrate.

Almaguer (2018) points to fan modding efforts as one way out of the trap. By breaking a game down to its atomic elements and exerting almost total control over a game world, the modder circumvents the problem of emergence. In modding a world, the gravity of the game 
swings from the system to the player-modder, who has the capacity to truly deterritorialize the game into something utterly different and which welcomes further deterritorialization. These "tactical games" (DyerWitheford and De Peuter 2009) have the potential to break free by exiting the emergent space. Yet as long as modding remains trapped in a broader, extractive platform ecosystem like Steam the problems remain the same; the tactical designer is absorbed and becomes a part of the "playbor force" (Dyer-Witheford and De Peuter 2009) once again.

We might point to the platform cooperativism movement as the platform analogue. The title of the volume assembled by Trebor Sholz and Nathan Schneider (2017) — Ours to Hack and to Own-certainly points to a shared hacker mentality between the movement and game modders. At its simplest level, the platform cooperativism movement aims at breaking down the the division between designer and user, vectoralist and subject, that drives the platform's insidious extractive function. At its most extreme, it represents a strategy for radically re-wiring the broader economic, political, and cultural ecosystem in which platforms operate by providing a viable alternative to the tech giants. Yet cooperativism is also plagued with insufficiencies and pitfalls. First is simple viability. As Taylor (2017) points out, "[history] abounds with rousing examples of cooperative projects, and almost as many failure" (p. 234). More seriously, one must question whether or not one can generate a truly equitable platform. One can pay employees a fair wage, take every possible step to ensure the safety of users' data, operate as transparently as possible, and still fail to achieve one's ideals simply because a platform is a platform; it can only function through extraction. Addressing concerns about privacy risks mistaking the symptoms for the disease. A shared platform must still extract data and segment the space of possibility.

Regardless, modding and cooperativism represent positive first steps toward identifying genuine strategies for the battle ahead by striking at the hidden rigidity of emergence. Only by pushing back on the myth of emergence as a liberating aesthetic can we begin to chart a truly radical space on in both games and platforms-or indeed whatever more egalitarian model may supplant platforms. We need forms of play and communication in which action does not generate an identical model, in which all our behaviors are not trapped within their own sameness and predictability. Certainly the potential for these technologies exist, it is simply up to us to discover what they are. Whatever comes may be stranger than we think. 


\section{References}

Alexander, Leigh (2013), "Spector: Go Emergent - Game Design Is Not All About You," Gamasutra, November 16 (accessed November 30, 2017), [available at https://ubm.io/2KLCG4E].

Almaguer, Jacob (2018), "Gamer Resistance to Marketization of Play," Markets, Globalization and Development Review, 3 (3), Special Issue, Article 5.

Baldwin, Kai (2018), "Virtual Avatars: Trans Experiences of Ideal Selves through Gaming," Markets, Globalization and Development Review, 3 (3), Special Issue, Article 3.

Baudrillard, Jean (2003), Passwords. New York: Verso.

Baudrillard, Jean (2010), Simulacra and Simulation. Ann Arbor, Ml: University of Michigan Press.

Bogost, Ian (2018), "My Cow Game Extracted Your Facebook Data," The Atlantic, March 22, (accessed July 22, 2018), [available at https://bit.ly/2A63JaP].

Bogost, Ian (2010), Persuasive Games: The Expressive Power of Videogames. Cambridge, MA: MIT Press.

Bogost, lan (2008), Unit Operations: An Approach to Videogame Criticism. Cambridge, MA: MIT Press.

Bratton, Benjamin H (2015), The Stack: On Software and Sovereignty. Cambridge, MA: MIT Press.

Brown, Stuart L. and Christopher C. Vaughan (2010), Play: How It Shapes the Brain, Opens the Imagination, and Invigorates the Soul. New York: Avery.

Cadwalladr, Carole (2018), "I Made Steve Bannon's Psychological Warfare Tool': Meet the Data War Whistleblower," The Guardian, March 18, (accessed June 2, 2018), [available at https://bit.ly/2HGFvCD].

Deleuze, Gilles (2009), "Postscript on the Societies of Control," in Media Studies: A Reader, Sue Thornham, Caroline Bassett and Paul Marris, eds. 3rd ed. New York: NYU Press, 89-93.

Deleuze, Gilles and Felix Guattari (2016), A Thousand Plateaus. Minneapolis, MN: University of Minnesota Press.

Dibbell, Julian (2006), Play Money. New York: Basic Books. 
Domanico, Anthony (2015), "Superfans Bring 'Game of Thrones' to Life in Minecraft," CNET, February 3, (accessed June 2, 2018), [available at https://cnet.co/1AwSrFi].

Dyer-Witheford, Nick and Greig De Peuter (2009), Games of Empire: Global Capitalism and Video Games. Minneapolis, MN: University of Minnesota Press.

Freire, Manuel, Ángel Serrano-Laguna, Borja Manero Iglesias, Iván Martínez-Ortiz, Pablo Moreno-Ger and Baltasar Fernández-Manjón (2016), "Game Learning Analytics: Learning Analytics for Serious Games," in Learning, Design, and Technology, Michael J Spector, Barbara B Lockee and Marcus D. Childress, eds. Cham: Springer, 1-29. https://doi.org/10.1007/978-3-319-17727-4 21-1

Frier, Sarah, and Mark Bergen (2018), "Google Wunderkind Is Building a Secret Social-Gaming Startup." Bloomberg, May 2, (accessed June 8, 2018), [available at https://bloom.bg/2jol9UB].

Galloway, Alexander R (2006), Gaming: Essays on Algorithmic Culture. Minneapolis, MN: University of Minnesota Press.

Galloway, Alexander R, and Eugene Thacker (2007), The Exploit: $A$ Theory of Networks. Minneapolis, MN: University of Minnesota Press.

Gibson, William (2012), Distrust That Particular Flavor. New York: Berkley Books.

Grubb, Jeff (2017), "Valve Won't Manually Curate Steam Because It Dominates PC Gaming," VentureBeat, February 13, (accessed June 8, 2018), [available at https://bit.ly/2fril7N].

Hardt, Michael and Antonio Negri (2000), Empire. Cambridge, MA: Harvard University Press.

"How to Launch a Digital Restaurant Loyalty Program." Grubhub.com, May 8, 2015, (accessed June 10, 2018), [available at https://bit.ly/2OYSF2C].

Isbister, Katherine (2016), How Games Move Us: Emotion by Design. Cambridge, MA: MIT Press.

Juul, Jesper (2005), Half-Real: Video Games between Real Rules and Fictional Worlds. Cambridge, MA: MIT Press.

Kaplan, Fred (2016), Dark Territory: The Secret History of Cyber War. New York: Simon and Schuster. 
Kent, Steven L. (2001), The Ultimate History of Video Games. New York: Three Rivers Press.

Mac, Kurt J "Minecraft Far Lands or Bust!" Minecraft Far Lands or Bust, (accessed on July 20, 2018), [available at www.farlandsorbust.com].

Lazzarato, Maurizio (1996), "Immaterial Labor," Generation Online, n.d. (accessed on May 20, 2018), [available at https://bit.ly/1nTfowP].

Levy, Pierre (1998), Becoming Virtual: Reality in the Digital Age. New York: Plenum Trade.

Morrison, Brice (2018), "The Next Surprise Billion Dollar Game Will Be On Alexa," Gamasutra, February 1, (accessed June 10, 2018), [available at https://ubm.io/2M5Y1uN].

Murray, Janet H. (2012), Inventing the Medium: Principles of Interaction Design as a Cultural Practice. Cambridge, MA: MIT Press.

Ndalianis, Angela (2004), Neo-Baroque Aesthetics and Contemporary Entertainment. Cambridge, MA: MIT Press.

Penny, Simon (2004), "Representation, Enaction, and the Ethics of Simulation," in First Person: New Media as Story, Performance, and Game, Noah Wardrip-Fruin and Pat Harrigan, eds. Cambridge, MA: MIT Press, 73-84.

Roh, Seunghwan, Kyoungwon Seo, Jiyoung Lee, Jihyo Kim, Hokyoung Blake Ryu, ChangHo Jung, HyunWoo Lee and JongHo Shin (2016), "Goal-Based Manufacturing Gamification: Bolt Tightening Work Redesign in the Automotive Assembly Line," in Advances in Ergonomics of Manufacturing: Managing the Enterprise of the Future: Proceedings of the AHFE 2016 International Conference on Human Aspects of Advanced Manufacturing, July 27-31, 2016, Walt Disney World, Florida, USA, Christopher Schlick and Stefan Trzcielinski, eds. Cham: Springer, 293-304. https://doi.org/10.1007/978-3-319-41697-7

Salen, Katie and Eric Zimmerman (2004), Rules of Play: Game Design Fundamentals. Cambridge, MA: MIT Press.

Schreier, Jason (2017), "Top Video Game Companies Won't Stop Talking About 'Games As A Service,"' Kotaku, May 30, (access June 10, 2018), [available at https://bit.ly/2vRsqCr].

Shah, Saqib (2017), "Belgium Moves to Ban 'Star Wars Battlefront 2'-Style 
Loot Boxes," Engadget, November 22, (accessed June 10, 2018), [available at https://engt.co/2AYutuc].

Scholz, Terbor and Nathan Schneider, eds (2017), Ours to Hack and to Own. New York: OR Books.

Srnicek, Nick (2017), Platform Capitalism. Malden, MA: Polity.

Taylor, Astra (2017), "Non-Cooperativism," in Ours to Hack and to Own, Trebor Scholz and Nathan Schreider, eds. New York: OR Books.

Terranova, Tiziana (2003), "Free Labor: Producing Culture For the Digital Economy," Electronic Book Review, June 20, (accessed on: June 18, 2018), [available at https://bit.ly/2w13qZB].

Wark, McKenzie (2007), Gamer Theory. Cambridge, MA: Harvard University Press.

Wark, McKenzie (2004), A Hacker Manifesto. Cambridge, MA: Harvard University Press.

Wijman, Tom (2018), "Mobile Revenues Account for More Than $50 \%$ of the Global Games Market as It Reaches \$137.9 Billion in 2018," Newzoo, April 30, (accessed on: June 10, 2018), [available at https://bit.ly/2HHIZcJ].

Zimmerman, Eric (2004), "Narrative, Interactivity, Play, and Games: Four Naughty Concepts in Need of Discipline," in First Person: New Media as Story, Performance, and Game, Noah Wardrip-Fruin and Pat Harrigan, eds. Cambridge, MA: MIT Press, 154-64. 